\title{
Evaluation of Effectiveness of Home Remedies for Toothbrush Decontamination using Vinegar and Vinegar with Common Salt
}

\author{
${ }^{1}$ Vinay Mavani, ${ }^{2}$ Karuna Y Mahabala, ${ }^{3}$ Ethel Suman, ${ }^{4}$ Srikant Natarajan, ${ }^{5} \mathrm{P}$ Anupama Nayak \\ ${ }^{6}$ Suprabha B Srikrishna, ${ }^{7}$ Arathi Rao
}

\begin{abstract}
Aim: The aim of the study was to evaluate if vinegar and vinegar with $3.5 \%$ sodium chloride could be used as an alternative to chlorhexidine gluconate for disinfection of toothbrushes.

Materials and methods: The study consisted of three groups: group I: $0.12 \%$ chlorhexidine digluconate, group II: $38 \%$ white vinegar, and group III: $38 \%$ white vinegar with $3.5 \%$ sodium chloride. Two new toothbrushes were cultured to check their sterility before use. Eight children in the age group of 6 to 12 years were given oral hygiene instructions and four sets of oral hygiene kits. At the end of the 1st week, one set of used toothbrushes was cultured to check for total viable count. Again at the end of the $2 \mathrm{nd}, 3 \mathrm{rd}$, and 4 th weeks, the $2 \mathrm{nd}$, 3rd, and 4th sets of brushes were collected, subjected to respective decontamination treatment for 12 hours, and then cultured for microbial analyses. The obtained data were analyzed using Fisher's exact test.
\end{abstract}

Results: In group I, three out of eight brushes showed 1 to 10,000 colonies, in group II, one out of eight cases showed $>10,000$ colonies and two out of eight showed 1 to 10,000 colonies, and in group III, all the eight cases showed no colonies upon culturing.

Conclusion: Out of all the tested decontaminating agents, combination of $38 \%$ white vinegar and $3.5 \%$ sodium chloride was found to be the most efficient.

Clinical significance: Toothbrushes become contaminated upon use and act as a reservoir for microorganisms. Thus, toothbrush decontamination should become a routine practice. Testing the disinfecting efficacy of vinegar and common salt is, thus, beneficial as they are available in every kitchen.

Keywords: Chlorhexidine, Decontamination, Sodium chloride, Toothbrushing, Vinegar.

How to cite this article: Mavani V, Mahabala KY, Suman E, Natarajan S, Nayak PA, Srikrishna SB, Rao A. Evaluation of

\footnotetext{
1,2,5-7Department of Pedodontics and Preventive Dentistry Manipal College of Dental Sciences, Manipal University Mangaluru, Karnataka, India

${ }^{3}$ Department of Microbiology, Kasturba Medical College Mangaluru, Karnataka, India

${ }^{4}$ Department of Oral Pathology and Microbiology, Manipal College of Dental Sciences, Mangaluru, Karnataka, India

Corresponding Author: Karuna Y Mahabala, Department of Pedodontics and Preventive Dentistry, Manipal College of Dental Sciences, Manipal University, Mangaluru, Karnataka India, Phone: +919964116229, e-mail: karuna.ym@manipal.edu
}

Effectiveness of Home Remedies for Toothbrush Decontamination using Vinegar and Vinegar with Common Salt. World J Dent 2018;9(1):19-23.

Source of support: Nil

Conflict of interest: None

\section{INTRODUCTION}

Toothbrushes are an integral part of any oral hygiene maintenance kit and toothbrushing plays a pivotal role in plaque control. ${ }^{1}$ On the contrary, toothbrushes can also serve as a reservoir for microorganisms and, thus, may play a significant role in causation and transmission of infection. ${ }^{2}$ This is because toothbrushes can become contaminated from the oral cavity, environment, hands, aerosol contamination, and storage containers. ${ }^{3}$

Depending on the source of contamination, toothbrushes can be vectors for transmission or reinfection of microorganisms causing oral diseases, such as dental caries, herpes, and periodontitis, ${ }^{4}$ and many other systemic conditions, such as respiratory, gastrointestinal, cardiovascular, and renal problems. ${ }^{2}$ Thus, the importance of toothbrush decontamination is evident.

A number of procedures have been mentioned in the literature for achieving the same, such as continuous brush exchange, ${ }^{5}$ submerging the brush into microbicide solutions, ${ }^{6}$ spraying antiseptic solutions, ${ }^{7}$ or using ozone or ultraviolet. ${ }^{8}$ Among the tested antiseptic solutions, chlorhexidine gluconate, cetylpyridinium chloride, sodium perborate, hydrogen peroxide, listerine, triclosan-containing dentifrice solution, and $2 \%$ sodium hypochlorite ${ }^{6,7,9-12}$ have been proven to be effective decontaminants for toothbrushes. However, the search is still on for a rapidly effective, cost-effective, nontoxic, and easily implementable suitable alternative. ${ }^{10}$

In this regard, when toothbrush decontaminating efficacy with $50 \%$ white vinegar was measured in vitro and in vivo, it has been found to be promising against the specifically tested bacteria. ${ }^{6,13}$ On the contrary, during exploration of food preservation techniques, it has also been proven that addition of $3.5 \%$ sodium chloride to vinegar increases the antibacterial activity. ${ }^{14}$ This present study is aimed to evaluate if vinegar with/without sodium 
chloride could be used as an alternative to chlorhexidine gluconate for disinfection of toothbrushes. The effect of $38 \%$ vinegar with $3.5 \%$ sodium chloride solution was compared with $38 \%$ vinegar as well as $0.12 \%$ chlorhexidine gluconate solutions on the total viable count present on the toothbrushes. The null hypothesis for the study was set as there is no difference in the toothbrush-decontaminating efficiency of $38 \%$ white vinegar with $3.5 \%$ sodium chloride and $38 \%$ white vinegar when compared with $0.12 \%$ chlorhexidine digluconate.

\section{MATERIALS AND METHODS}

This experimental in vivo intergroup comparative crossover study was initiated after approval from the Institutional Ethics Committee. Procedures followed in the study were in accordance with the Helsinki declaration of 1975 that was revised in 2000.

\section{Sample Size}

As per the study conducted by Komiyama et $\mathrm{al}^{6}{ }^{6}$ a group sample size of 4 achieved $89 \%$ power to detect a difference of $-4,414,400.0$ between the null hypothesis and the alternative hypothesis with a significance level (alpha) of 0.05 using a two-sided two-sample t-test. However, considering the possible attrition and the microbial contamination, the sample size was taken as eight per group.

The study consisted of three groups: group I: $0.12 \%$ chlorhexidine digluconate, group II: 38\% white vinegar, and group III: $38 \%$ white vinegar with $3.5 \%$ sodium chloride.

\section{Study Center}

The study was conducted at the Department of Pedodontics and Preventive Dentistry and Department of Microbiology.

\section{Inclusion and Exclusion Criteria}

Eight children in the age group of 6 to 12 years from a local school were selected using random sampling technique for the study. Informed consent was obtained after explaining the study purpose and the procedure to the selected children and their parents. Furthermore, permission was obtained from the headmaster of the school. Children whose general health was good, who had at least 20 natural teeth per arch, who complied with the toothbrushing instructions, and who had decayed, missing, and filled teeth/dft $<5$ were included in the study. Children who were on antibiotics 3 months before the study, who were undergoing orthodontic treatment, and who had removable intraoral prosthesis during the study period were excluded from the study. 11,12

\section{Procedure}

All the study participants were provided with four sets of oral hygiene kit containing a soft-bristled toothbrush and a fluoridated dentifrice. Before the study, two fresh toothbrushes identical to the brushes distributed among the study participants were subjected to microbial analyses to determine the total viable count, if any.

\section{Preintervention Proceedings}

All the study participants were demonstrated the standardized brushing technique by the principal investigator and were asked to brush teeth as well as tongue using a toothbrush to ensure uniformity. Instructions were given to brush twice daily (in the morning and at night using a pea-sized toothpaste) for about 2 minutes with the assigned toothpaste and toothbrush for a period of 1 week. Following brushing, they were asked to rinse their toothbrush in running tap water for 30 seconds and thereafter place the brush in an open brush holder, bristles up, outside the bathroom. After 1 week, all the study participants were instructed to bring their toothbrushes in sterile plastic pouches given to them, which were collected by the investigator. All the toothbrushes were number coded and were subjected to bacterial extraction.

\section{Bacterial Extraction}

The toothbrushes were kept immersed in nutrient broth. After three logarithmic dilutions in nutrient broth, culturing was done on nutrient agar for the total viable count. The plates were incubated at $37^{\circ} \mathrm{C}$ for 24 hours. The number of colonies, measured as colony-forming units, were counted and recorded. The microbial analysis was performed by the microbiologist who was blinded to the study procedure.

\section{Intervention using Different Decontamination Procedures}

The same study participants were again made to brush teeth and tongue for three consecutive weeks using three new brushes (1 toothbrush for 1 week). On every 8th day, brushes were collected from them in a sterile plastic pouch. The collected contaminated toothbrushes were kept immersed in $0.12 \%$ chlorhexidine digluconate (1st week toothbrushes), 38\% white vinegar (2nd week toothbrushes), and 38\% white vinegar with $3.5 \%$ sodium chloride (3rd week toothbrushes) for 12 hours.

\section{Postdecontamination Microbial Analysis}

After 12 hours, the toothbrushes were again subjected to bacterial extraction as described previously to determine the efficacy of various decontamination procedures. ${ }^{11,12}$ 


\section{RESULTS}

When the obtained data were analyzed using Fisher's exact test, there was a significant difference in the colony count between all the groups ( $\mathrm{p}<0.001$; Table 1 and Graph 1$)$. About $83.3 \%$ of the cases showed $>10^{4}$ colonies when toothbrushes were cultured without any decontamination procedure (negative control). In group I (positive control), three out of eight brushes showed 1 to 10,000

Table 1: Groups vs colony count cross-tabulation

\begin{tabular}{|c|c|c|c|c|}
\hline \multirow[b]{2}{*}{ Groups } & \multicolumn{3}{|c|}{ Colony count } & \multirow[b]{2}{*}{ Total } \\
\hline & 0 & $1-10^{4}$ & $>10^{4}$ & \\
\hline \multicolumn{5}{|l|}{ New toothbrushes } \\
\hline Count & 2 & 0 & 0 & 2 \\
\hline$\%$ Within colony count & 10.0 & 0 & 0 & 5.9 \\
\hline \multicolumn{5}{|c|}{ Group I (positive control group) } \\
\hline Count & 5 & 3 & 0 & 8 \\
\hline$\%$ Within colony count & 25.0 & 37.5 & 0 & 23.5 \\
\hline \multicolumn{5}{|l|}{ Group II } \\
\hline Count & 5 & 2 & 1 & 8 \\
\hline$\%$ Within colony count & 25.0 & 25.0 & 16.7 & 23.5 \\
\hline \multicolumn{5}{|l|}{ Group III } \\
\hline Count & 8 & 0 & 0 & 8 \\
\hline$\%$ Within colony count & 40.0 & 0 & 0 & 23.5 \\
\hline \multicolumn{5}{|l|}{ Negative control } \\
\hline Count & 0 & 3 & 5 & 8 \\
\hline$\%$ Within colony count & 0 & 37.5 & 83.3 & 23.5 \\
\hline \multicolumn{5}{|l|}{ Total } \\
\hline Count & 20 & 8 & 6 & 34 \\
\hline$\%$ Within colony count & 100.0 & 100.0 & 100.0 & 100.0 \\
\hline
\end{tabular}

Fisher's exact test value $=20.950, p<0.001$ colonies, whereas in group II, one out of eight cases showed $>10^{4}$ colonies and two out of eight showed 1 to $10^{4}$ colonies. In group III, all the eight cases showed no colonies upon culturing (Fig. 1).

\section{DISCUSSION}

It has been well documented in the literature that toothbrushes are excellent locations for the growth of microorganisms, ${ }^{15}$ and after each brushing, there is an actual risk of recolonization. ${ }^{1}$ Contaminated toothbrushes are the major source of repeated infection of the oral cavity. ${ }^{11}$ Along with a better understanding of oral diseases due to toothbrush contamination, the awareness about the association of contaminated toothbrushes and systemic infections has also increased in the recent years. Thus,

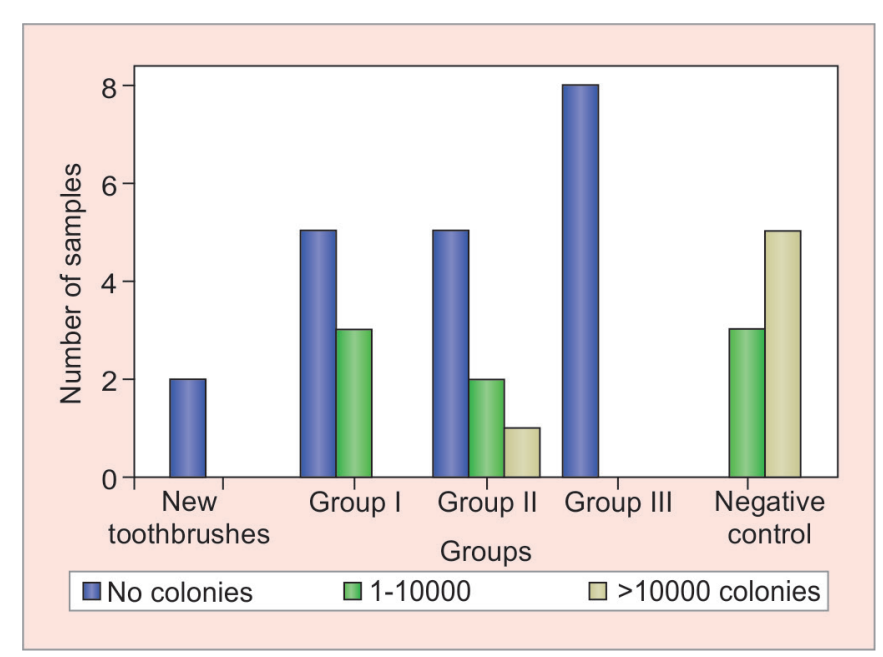

Graph 1: Difference in the colony count in each group
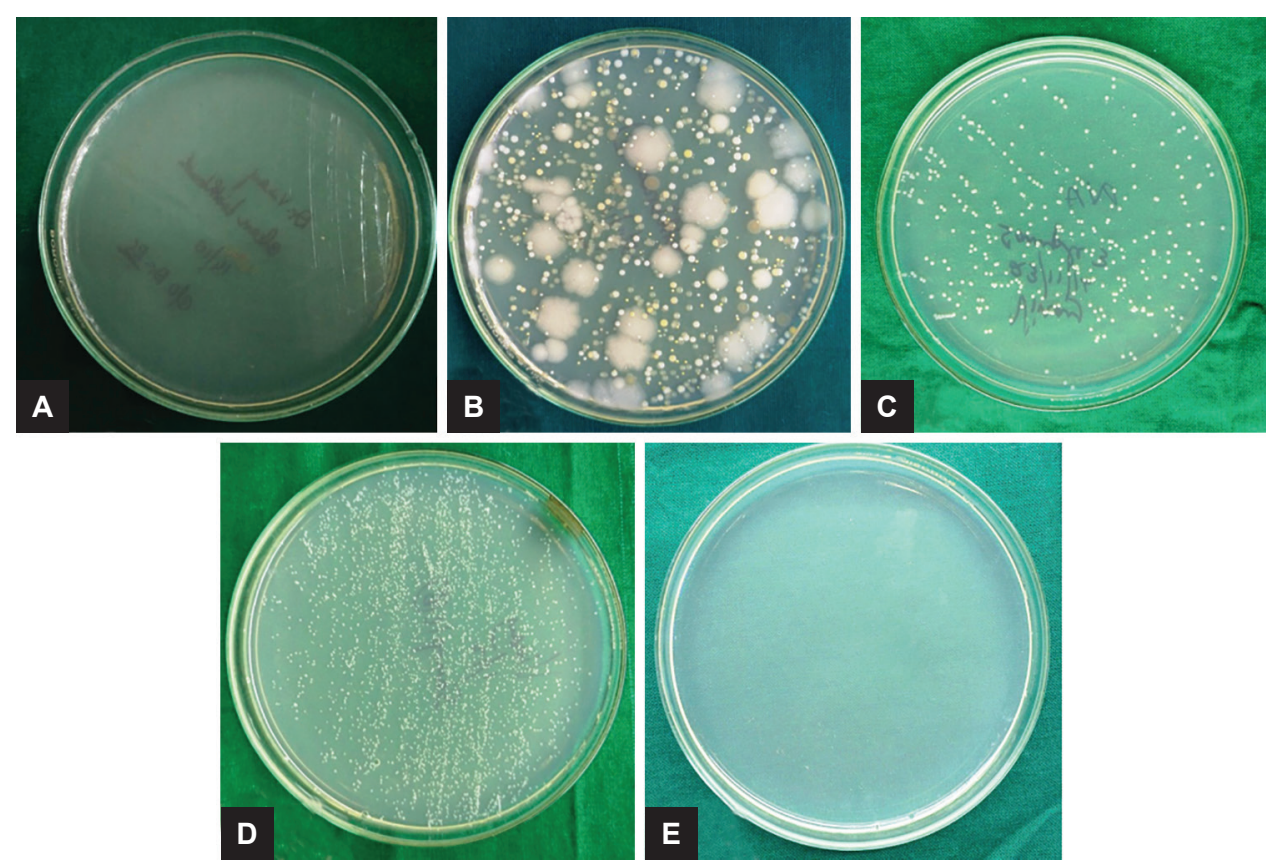

Figs 1A to E: Total viable count seen on: (A) New toothbrushes; (B) negative control; (C) group I; (D) group II; and (E) group III 
various methods of toothbrush decontamination were tried. ${ }^{5-12}$ Considering that the proposed methods for toothbrush disinfection reported in the literature are either expensive or cannot be easily implemented, the present study was conducted to evaluate the effectiveness of the household remedies like decontamination of toothbrushes using vinegar and vinegar with salt. We chose a cross-over study design as it has advantages over parallel study design. Since cross-over study involves within-subject comparisons, there is an increase in the precision of observations as the effect of confounding factors, such as age and dietary factors are nullified. Furthermore, a small sample size is required while doing cross-over studies. ${ }^{16}$

In the present study, when new toothbrushes were cultured to assess their level of contamination before using both, the cultured brushes were found to be sterile. However, when the negative controls (used toothbrushes without any decontamination procedure) were cultured, all the brushes showed microbial growth with $83 \%$ of the brushes having more than $10^{4}$ colonies. This finding signifies that toothbrushes become contaminated following use and routinely followed storage conditions. This is in accordance with various authors, who showed the significant bacterial retention and survival on toothbrushes after use. ${ }^{17-19}$

Chlorhexidine has been used in various forms like solution and sprays for the decontamination of the toothbrushes, and found to be efficient. ${ }^{4,11,15}$ Thus, we chose to use $0.12 \%$ chlorhexidine digluconate as a positive control. Results of our study showed that $0.12 \%$ chlorhexidine digluconate is effective in decontaminating the toothbrushes, thus supporting the conclusions of the previous studies. ${ }^{4,11,15}$ However, in our study, 38\% white vinegar and the combination of $38 \%$ white vinegar and $3.5 \%$ sodium chloride were found to be more efficient.

The vinegar is a sour and astringent liquid, the principal component of which is acetic acid. This product is inexpensive and easily available in the market. ${ }^{20}$ For more than 2000 years, vinegar has been used to flavor and preserve foods, heal wounds, fight infections, clean surfaces, and even to manage diabetes. ${ }^{21}$ The disinfecting property of the vinegar due to the acetic acid content of it makes it useful for the treatment of oral inflammation (as mouthwash) and as an antiseptic for sores. The acetic acid is an organic acid, which is a weak acid. At neutral $\mathrm{pH}$, they passively diffuse through the bacterial cell wall and dissociate into anions and protons. Discharge of the protons causes a reduction in the internal $\mathrm{pH}$, which, in turn, represses the bacteria. ${ }^{22}$ The antibacterial activity of vinegar against four out of five tested microorganisms inhabiting the oral cavity (Streptococcus mutans,
Staphylococcus aureus, Enterococcus faecalis, and Candida albicans) was found to be superior to the chlorhexidine in a study conducted by Mohammed El-Shamy et $\mathrm{al}^{22}$ and they concluded that vinegar appears to satisfy all of the criteria for antibacterial agents. When Komiyama et $\mathrm{al}^{6}$ evaluated the disinfecting efficacy of $50 \%$ white vinegar as compared with $0.12 \%$ chlorhexidine digluconate, vinegar showed a significant reduction of all the tested microorganisms colonized on the toothbrush except $C$. albicans. However, they concluded that chlorhexidine was a more efficient disinfectant, which is contradicting the results of our study. This could be due to the difference in the methodology followed, where in their study, the toothbrushes were contaminated in vitro using artificial microbial solutions and the disinfecting ability of the solutions used was tested against specific bacteria. The present study took place under in vivo conditions, where toothbrushes were cultured after the children had brushed using them, and the total viable count on the brush was counted postbrushing and postdisinfection. We used $38 \%$ white vinegar as $50 \%$ white vinegar was not readily available in the Indian market. Better disinfecting ability was shown by white vinegar in our studydespite lower concentration. This showed that even 38\% white vinegar can be used for disinfection of toothbrushes.

Another finding of the present study is that the combination of $38 \%$ white vinegar and $3.5 \%$ sodium chloride achieved near-total decontamination of all the toothbrushes. The addition of $3.5 \%$ sodium chloride enhanced the antibacterial action of vinegar against food-borne pathogenic bacteria including Escherichia coli O157:H7 in the study conducted by Entani et al. ${ }^{14}$ In the presence of sodium chloride, the potential of amino compounds, which protect the bacterial cell from direct contact with antimicrobial agents, becomes weakened. Thus, these cells become more susceptible to the action of the antimicrobial agents. It has also been reported that with a higher saline concentration, a greater bacterial surface hydrophobicity may facilitate antimicrobial solution penetration or contact with the microorganism. ${ }^{23}$

Although the American Dental Association recommends to change the toothbrushes every 3 months, ${ }^{4}$ it is not routinely followed due to psychological, economic, and environmental barriers. Thus, establishing an easy and effective method for disinfecting a toothbrush becomes important. According to the results of this study, a combination of vinegar and common salt is an effective method to disinfect the contaminated toothbrushes, which is also easy, safe, and economical. However, future studies need to be conducted using this combination at different concentrations of white vinegar and sodium chloride. 


\section{CONCLUSION}

- Toothbrushes that are not decontaminated after toothbrushing are highly colonized with microorganisms.

- Immersion in 38\% white vinegar and 3.5\% sodium chloride, $38 \%$ white vinegar, and $0.12 \%$ chlorhexidine digluconate solutions for 12 hours resulted in the decontamination of the toothbrushes in a decreasing order of efficiency.

\section{CLINICAL SIGNIFICANCE}

Toothbrushes become contaminated upon use and act as a reservoir for microorganisms. Thus, toothbrush decontamination should become a routine practice. Testing the disinfecting efficacy of vinegar and common salt is, thus, beneficial as they are available in every kitchen.

\section{REFERENCES}

1. Gujjari SK, Gujjari AK, Patel PV, Shubhashini PV. Comparative evaluation of ultraviolet and microwave sanitization techniques for toothbrush decontamination. J Int Soc Prev Community Dent 2011 Jan-Jun;1(1):20-26.

2. Glass RT. The infected toothbrush, the infected denture, and transmission of disease: a review. Compendium 1992 Jul;13(7):592, 594, 596-598.

3. Frazelle MR, Munro CL. Toothbrush contamination: a review of the literature. Nurs Res Pract 2012 Jan;2012:420630.

4. Nelson Filho P, Macari S, Faria G, Assed S, Ito IY. Microbial contamination of toothbrushes and their decontamination. Pediatr Dent 2000 Sep-Oct;22(5):381-384.

5. Pai V. Effect of a single-use toothbrush on plaque micro flora. Indian J Dent Res 2009 Oct-Dec;20(4):404-406.

6. Komiyama EY, Back-Brito GN, Balducci I, Koga-Ito CY. Evaluation of alternative methods for the disinfection of toothbrushes. Braz Oral Res 2010 Jan-Mar;24(1):28-33.

7. Sato S, Pedrazzi V, Guimarães Lara EH, Panzeri H, Ferreira de Albuquerque R Jr., Ito IY. Antimicrobial spray for toothbrush disinfection: an in vivo evaluation. Quintessence Int 2005 Nov-Dec;36(10):812-816.

8. Bezirtzoglou E, Cretoiu SM, Moldoveanu M, Alexopoulos A, Lazar V, Nakou M. A quantitative approach to the effectiveness of ozone against micro biota organisms colonizing toothbrushes. J Dent 2008 Aug;36(8):600-605.

9. SatoS, Ito IY, Lara EH, PanzeriH, Albuquerque RFJr, Pedrazzi V. Bacterial survival rate on toothbrushes and their decontamination with antimicrobial solutions. J Appl Oral Sci 2004 Apr-Jun;12(2):99-103.
10. Bonesvoll P, Gjermz P. A comparison between chlorhexidine and some quaternary ammonium compounds with regard to retention, salivary concentration and plaque-inhibiting effect in the human mouth after mouth rinses. Arch Oral Biol 1978 Feb;23(4):289-294.

11. Bhat SS, Hegde KS, George RM. Microbial contamination of tooth brushes and their decontamination. J Indian Soc Pedod Prev Dent 2003 Sep;21(3):108-112.

12. Tomar P, Hongal S, Saxena V, Jain M, Rana K, Ganavadiya R. Evaluating sanitization of toothbrushes using ultraviolet rays and $0.2 \%$ chlorhexidine solution: a comparative clinical study. J Basic Clin Pharm 2014 Dec;6(1):12-18.

13. Basman A, Peker I, Akca G, Alkurt MT, Sarikir C, Celik I. Evaluation of toothbrush disinfection via different methods. Braz Oral Res 2016;30(1):e6.

14. Entani E, Asai M, Tsujihata S, Tsukamoto Y, Ohta M. Antibacterial actin of vinegar against food-borne pathogenic bacteria including Escherichia coli O157:H7 (Part 2). Effect of sodium chloride and temperature on bactericidal activity. Kansenshogaku Zasshi 1997 May;71(5):451-458.

15. Rodrigues LA,MotterCW,PegoraroDA,MenoliPV,MenolliRA. Microbiological contamination of toothbrushes and identification of a decontamination protocol using chlorhexidine spray. Rev Odonto Cienc 2012;27(3):213-217.

16. Wang D, Lorch U, Bakhai A. Crossover trials. In: Wang D, Bakhai A, editors. Clinical trials a practical guide to design, analysis, and reporting. Spain: Remedica Press; 2006. pp. 91-99.

17. Glass RT, Lare MM. Toothbrush contamination: a potential health risk? Quintessence Int 1986 Jan;17(1):39-42.

18. Grewal N, Swaranjit K. A study of toothbrush contamination at different time intervals and comparative effectiveness of various disinfecting solutions in reducing toothbrush contamination. J Indian Soc Pedod Prev Dent 1996 Mar;14(1):10-13.

19. Karibasappa GN, Nagesh L, Sujatha BK. Assessment of microbial contamination of toothbrush head: an in vitro study. Indian J Dent Res 2011 Jan-Feb;22(1):2-5.

20. Pinto TM, Neves AC, Leão MV, Jorge AO. Vinegar as an antimicrobial agent for control of Candida spp. In complete denture wearers. J Appl Oral Sci 2008 Nov-Dec;16(6): 385-390.

21. Johnston CS, Gaas CA. Vinegar: medicinal uses and antiglycemic effect. MedGenMed 2006 May;8(2):61.

22. Mohammed El-Shamy FM, Singh G, Elraih H, Gupta I, Sharawy A. In vitro antimicrobial effectiveness of vinegar against oral microorganisms: part I. J Int Oral Health 2016 Jan 8(11):999-1002.

23. Angienda PO, Hill DJ. The effect of sodium chloride and $\mathrm{pH}$ on the antimicrobial effectiveness of essential oils against pathogenic and food spoilage bacteria: implications in food safety. Int Sch Sci Res Innov 2011 Jan;5(9):572-577. 